\title{
O Museu de Favela e a produção do espaço no Pavão-Pavãozinho e Cantagalo (Rio de Janeiro/RJ)
}

\author{
Museu de Favela and the and space production in \\ Pavão-Pavãozinho and Cantagalo (Rio de Janeiro/RJ)
}

Aline dos Santos Portilho*

\author{
Palavras-chave: \\ Museu de Favela \\ Território \\ Práticas Espacializantes
}

Keywords

Museu de Favela

Territory

Spatial Practices

\begin{abstract}
Resumo: O artigo apresenta reflexões sobre as "práticas espacializantes" desenvolvidas por sujeitos mobilizados em torno do Museu de Favela (MUF). Serão tomadas como fontes para a análise as representações instituídas no livro "Circuito das Casas-Tela, caminhos de vida no Museu de Favela" (2012). Dialogando com os trabalhos de Michel De Certeau (2011) e Benedict Anderson (2008), procura-se, a partir dos conceitos de "espaço" e "comunidades imaginadas", problematizar as maneiras pelas quais estes sujeitos, ao cooperarem para a proposição de ações de resgate e registro de memórias dos moradores e das favelas, acabam por desencadear práticas que fazem daquele lugar, espaço, propondo também novas imaginações para aquela comunidade.
\end{abstract}

\begin{abstract}
The article presents reflections about "spacial practices" developed by individuals mobilized around the Museu de Favela (MUF). Will be taken as sources for the analysis the representations instituted in the book "Circuito das Casas-Tela, caminhos de vida no Museu de Favela" (2012). Dialoging with the works of Michel De Certeau (2011) and Benedict Anderson (2008), it is sought, from the concepts of "space" and "imagined communities", to problematize the ways in which these subjects, by cooperating for the proposition actions of rescue and registration of memories of the residents and shanty towns, end up triggering practices that make of that place, space, also proposing new visions for that community.
\end{abstract}

Recebido em 31 de maio de 2018. Aprovado em 02 de agosto de 2018.

Michel De Certeau, no livro $A$ invenção do cotidiano, afirma que "espaço é lugar praticado" (DE CERTEAU, 2011, p. 184). Assim, “[...] a rua geometricamente definida por um urbanismo é transformada em espaço pelos pedestres. Do mesmo modo, a leitura é o espaço produzido pela prática no lugar constituído por um sistema de signos um escrito" (DE CERTEAU, 2011, p. 184). O autor propõe passar "das estruturas às ações"; para isso, sua reflexão se concentra nas "ações narrativas" que produzem o espaço. Ou seja, concentra-se nas "práticas espacializantes", que são “[...] algumas formas elementares das práticas organizadoras de espaços: a bipolaridade 'mapa' e 'percurso', os processos de delimitação ou de 'limitação' e as 'focalizações enunciativas' (ou seja, o índice do corpo no discurso)" (DE CERTEAU, 2011, p. 183-184).

Seguindo este pensamento, proponho refletir sobre como, a partir de um território estabelecido geográfica, política e economicamente - os morros do Pavão-Pavãozinho e Cantagalo -, determinados usuários cooperam para a proposição de práticas que fazem daquele lugar, espaço, que serão tomadas ao longo do artigo como “práticas espacializantes". O foco da análise estará principalmente nas ações que são efetivadas pelos gestores do Museu de Favela, não desconsiderando, porém, a contribuição de agentes do governo e

\footnotetext{
* Doutora em História, Política e Bens Culturais pelo Centro de Pesquisa e Documentação de História Contemporânea do Brasil da Fundação Getulio Vargas (CPDOC/FGV). Produtora Cultural no Instituto Federal Fluminense, Campus Campos Centro. Pesquisadora do Núcleo de Estudos Culturais, Estéticos e Linguagens (NECEL). E-mail: asportilho@gmail.com
} 
membros de outras organizações da sociedade neste processo.

Pretendo chamar atenção, ao longo deste artigo, para o conjunto específico de práticas propostas pelos operadores do MUF que produzem as favelas do Pavão-Pavãozinho e Cantagalo como um espaço com uma significação específica e que coloca questões tanto sobre a representação das favelas quanto sobre a historicidade desta construção. Considero que toda prática humana em determinado lugar o torna espaço. Desse modo, não pretendo afirmar que aquelas favelas apenas se tornaram espaço a partir da ação do MUF. Pelo contrário, as diversas práticas realizadas naquelas favelas, ao longo da existência de cada uma, produziram-nas de tal modo carregado de significação que, inclusive, permitiram aos gestores do MUF introduzir novidades neste processo, reafirmando ou desafiando as antecedentes.

De modo articulado a esta ideia, é possível entender este empreendimento como a construção de uma "comunidade imaginada", seguindo a proposição de Benedict Anderson. Afirma o autor que "[...] na verdade, qualquer comunidade maior que a aldeia primordial do contato face a face (e talvez mesmo ela) é imaginada. As comunidades se distinguem não por sua falsidade/autenticidade, mas pelo estilo em que são imaginadas" (ANDERSON, 2008, p. 33). A investigação de Anderson é sobre a produção dos nacionalismos, desnaturalizando seus processos, o que guarda importante distância de tempo e escala do objeto aqui analisado. Ainda assim, entendo que suas proposições possam ajudar a refletir sobre os empreendimentos realizados pelo MUF uma vez que o ponto que nos interessa da reflexão do autor não é a discussão propriamente dos nacionalismos, mas a maneira como se engendram os mecanismos de constituição de comunidades.

Lilia Moritz Schwarcz, na apresentação à edição brasileira do livro de Anderson (2008), afirma uma defesa do uso do termo "imaginação" e da relevância do trabalho daquele autor para o estabelecimento desta definição. Afirma Schwarcz que "[...] mais que inventadas, nações são 'imaginadas', no sentido de que fazem sentido para a 'alma' e constituem objetos de desejo e projeções" (ANDERSON, 2008, p. 10).
Anderson analisa a utilização do censo, do mapa e do museu como instrumentos do Estado colonial para produzir a imaginação de seus domínios no Sudeste asiático. Afirma que este "estilo de criação imaginária não nasceu do nada" e é profundamente tributário das tecnologias desenvolvidas no período para a expansão colonial e a dominação de suas conquistas (ANDERSON, 2008, p. 254). Afirma, ainda, o autor que "[...] o mapa e o censo modelaram a gramática que, no devido tempo, possibilitaria o surgimento da 'Birmânia' e dos 'birmanianos', da 'Indonésia' e dos 'indonésios"' (ANDERSON, 2008, p. 254). Ou seja, são as tecnologias que produzem os entes que julgamos estarem apenas descrevendo e nomeando. Mas, a consolidação desta imaginação somente foi possibilitada pela instituição do museu, responsável pelo "tipo específico de criação de imagens do Estado colonial em relação à história e ao poder" (ANDERSON, 2008, p. 254).

Salienta-se que a produção desses instrumentos institui uma gramática do poder que não se restringe à experiência específica da colonização do Sudeste asiático. O termo imaginação remete, fundamentalmente, àquele agrupamento de indivíduos que, embora desconhecido em sua quase totalidade, comunga de uma identidade produzida pela imaginação. Nesse sentido, experiências como a do Museu de Favela são tentativas de apropriação de instrumentos como o mapa e o museu, como forma de amplificar as possibilidades de suas "maneiras de operar" (DE CERTEAU, 2011) a partir de uma busca por constituir novas imaginações para sua comunidade. $\mathrm{O}$ uso destes instrumentos tem por objetivo, justamente, mobilizar a identificação dos habitantes do Pavão-Pavãozinho e Cantagalo utilizando-se especialmente da memória.

\section{O Museu de Favela}

O Museu de Favela foi fundado no ano de 2008, como uma Organização Não Governamental (ONG). Sua existência resulta da mobilização de parcela dos moradores em torno das ações do Programa de Aceleração do Crescimento (PAC), fruto de parceira entre governo federal e estadual e iniciado 
no Pavão-Pavãozinho e Cantagalo em novembro de 2007. No âmbito do PAC, propunha-se realizar investimentos em infraestrutura e desenvolver ações que possibilitassem o desenvolvimento econômico e social local. ${ }^{1}$ Entre as obras de infraestrutura, estavam previstas a requalificação do "Beco do Amor Perfeito", que abre acesso entre Copacabana e o Pavão-Pavãozinho, ampliação das galerias de drenagem pluvial, ampliação do reservatório de água potável e construção de 120 apartamentos para o reassentamento de famílias cujas casas foram atingidas pelas obras do programa. ${ }^{2}$

Pelo Programa, criou-se, também, a Base de Inserção Social e Urbana (BISU), um escritório dirigido pela KAL Projetos e Territórios, empresa de arquitetura que desenvolve ações de intervenção social atreladas à intervenção urbana. O objetivo deste escritório era estabelecer estratégias de desenvolvimento econômico e social local, que ficariam conhecidas como "trabalho social do PAC". Dentre os associados da KAL Projetos e Territórios, estava Kátia Loureiro, que posteriormente faria parte da diretoria do MUF.

O Conselho Comunitário do PAC(CCOMP) foi o espaço criado dentro do PAC para estabelecer a interlocução entre gestores do programa $\mathrm{e}$ moradores com o objetivo de discutir com a comunidade local as diretrizes das intervenções, assegurando o princípio da participação àqueles que serão atingidos pelas obras. A partir das reuniões deste conselho, diversos moradores começaram a se aproximar das ações do trabalho social promovidas no BISU, dentre as quais estava a realização de cursos de qualificação profissional que colaborassem para a criação de um "legado do PAC" para aquelas favelas. Este legado consistia na criação de uma empresa, associação ou cooperativa que, após o término da execução do PAC, permanecesse no território e gerasse trabalho e renda para a população.

Como resultado dos debates do CCOMP, que reunia moradores, gestores públicos e a empresa KAL, e incorporava ideias de ambos, boa parte das ações foi direcionada para a criação de um museu que operasse também o turismo. Foram realizados, entre outros, dois cursos em parceria com a Universidade Federal do Estado do Rio de Janeiro (Unirio), um de Museologia e outro de
Turismo para moradores interessados em se engajar na criação daquele museu.

Em decorrência dessas ações, foi formada uma Comissão Pró-Museu composta por dois moradores do Cantagalo, Rita de Cássia e Sidney Silva; e dois moradores do Pavão-Pavãozinho, Carlos Esquivel, conhecido como Acme, e Valdete Viana. Esta comissão registrou, por meio de entrevistas, as memórias dos moradores mais antigos das duas favelas e frequentou os cursos acima citados. Dessa maneira, o museu começou a ser organizado.

O MUF é uma associação de direito privado sem fins lucrativos, o que lhe confere o caráter de associação de utilidade pública. É definido por seus gestores como um "museu territorial e vivo sobre memórias e patrimônio cultural de favela". $\mathrm{O}$ termo museu de território, ou territorial, integra o campo semântico articulado pela noção de museologia social e define experiências nas quais o acervo se compõe não apenas de objetos, mas do próprio território que opera. Essa definição também articula uma noção ampliada de patrimônio a que se presta preservar. Associada à ideia de museu comunitário, designa aqueles empreendimentos cujos patrimônios são reconhecidos

[...] como tal pela comunidade e por seus membros. É o capital cultural coletivo da comunidade. Ele é vivo, evolutivo, em permanente criação. Os responsáveis do museu utilizarão esse capital para atividades inscritas na dimensão cultural do desenvolvimento do território e da comunidade. A conservação é uma responsabilidade e uma tarefa coletiva da comunidade, os profissionais do museu sendo essencialmente apoio técnico e científico. (VARINE, 2005).

Ao definir seu empreendimento como museu de território, os promotores do MUF buscam colocar no centro de suas preocupações o espaço produzido pelas ações que desenvolvem. Além disso, por ser um empreendimento que valoriza os patrimônios das favelas entendidos como capital por aqueles que as habitam, a relação dos moradores com o espaço da favela será também central nas ações desenvolvidas pelo MUF. 
Estas ações se orientam pela produção de uma memória coletiva em conjunto com os moradores das duas favelas a partir da qual seja possível erguer nova representação para aqueles territórios. Os gestores do museu procuram construir essa nova representação deslocandose da chave da violência associada à carência que, frequentemente, marca a discursividade produzida em torno da favela.

Licia do Prado Valladares (2005), investigando a "construção social das representações das favelas" (p. 23), aponta como, já em sua origem, a favela foi interpretada como uma presentificação do "mundo rural na cidade" (p. 22). Segundo a autora, o mito de origem da favela se alimenta da imagem de Canudos produzida no livro "Os Sertões”, de Euclides da Cunha. Essa imagem “[...] também corresponde àquela vislumbrada pelos primeiros visitantes da favela do Rio, quando transpuseram em suas descrições a dualidade 'litoral versus sertão' para a dualidade 'cidade versus favela"' (VALLADARES, 2005, p. 23).

Esta construção alimentou a percepção da favela como problema, designação que, segundo a autora, qualificou esta formação urbana desde o seu surgimento. Afirma Valladares (2005, p. 36) que: "[...] a descoberta da favela foi logo seguida por sua designação como problema a ser resolvido. Aos escritos de jornalista vêm juntar-se vozes de médicos e engenheiros, preocupados com o futuro da cidade e sua população”; ademais, “[...] a 'problematização' precedeu a extensão do fenômeno ao conjunto da cidade e ocorreu enquanto o processo de favelização ainda não se havia generalizado na capital federal". E, ainda, "[...] essa problematização contou com forte respaldo do diagnóstico higienista aplicado à pobreza e ao cortiço, servindo este como uma das matrizes das primeiras representações da favela" (VALLADARES 2005, p. 39).

Essa visão sobre a favela, amparada em discursos científicos e técnicos, como os da medicina e da engenharia, por exemplo, cooperou para a consolidação da representação da favela como o lugar da ausência e da carência. Ou seja, a favela era, segundo aquela visão, o avesso da cidade que se desejava construir. Esta visão está na base da discursividade sobre as favelas ainda hoje e é justamente com ela que o MUF concorre na produção de suas ações.

\section{Produzindo imaginações para o Pavão-Pavãozinho e Cantagalo através do livro "Circuito das Casas- Tela” e dos mapas do MUF}

No ano de 2012, foi produzido o livro "Circuito das Casas Tela: caminhos de vida no Museu de Favela”. É uma produção do próprio museu, que foi financiada pelo Instituto Brasileiro de Museus (Ibram), através do Programa Pontos de Memória, e em parceria com a Organização dos Estados Iberoamericanos para a Educação, a Ciência e a Cultura (OEI). ${ }^{5}$ Seus três autores participaram da fundação do museu e permaneceram por algum tempo na sua direção. Acme, morador do Pavão-Pavãozinho e grafiteiro de reconhecimento internacional, foi presidente do MUF em sua primeira gestão e desligou-se da instituição em 2012. Kátia Loureiro, então moradora de Ipanema, era dona da empresa KAL Engenharia, responsável pelos projetos do PAC Social, ação a partir da qual ocorreram as articulações que deram origem ao MUF e se desligou do museu em 2013. Rita Santos, moradora do Cantagalo, continua pertencendo ao quadro do museu como Diretora Social e "curadora de memórias". As cópias do livro foram distribuídas gratuitamente para moradores de Pavão-Pavãozinho e Cantagalo e durante o $5^{\circ}$ Fórum Nacional de Museus. A obra está também disponível para compra na Base Operacional do museu.

O livro é assinado pelos três; porém, ao mesmo tempo, é uma publicação chancelada pelo museu. Ou seja, é uma leitura produzida por agentes autorizados a falar em nome da instituição, o que nos permite pensá-lo como uma representação institucional do MUF. É composto por 12 capítulos e seu projeto gráfico tem o grafite como referência estética fundamental. Há duas apresentações, uma assinada pelo então presidente do Ibram José Nascimento e outra assinada pelos três autores. O prefácio é assinado por Mário Chagas, "[...] poeta, museólogo e doutor em Ciências Sociais. 
Professor da Unirio e da ULHT [Universidade Lusófona de Humanidades e Tecnologia - Lisboa]" (LOUREIRO; PINTO; SILVA, 2012, p. 14). O texto não revela, porém, Mario Chagas havia sido diretor do Departamento de Processos Museais do Ibram, até meses antes do lançamento do livro. Do Departamento, fazia parte a Coordenação de Museologia Social e Educação, responsável pela condução do Programa Pontos de Memória.

A presença de textos destes agentes governamentais no livro demonstra que o modo como se produz esta representação decorre da inter-relação com as políticas de governo. Esse aspecto também fica evidente quando analisamos a dedicatória e os agradecimentos. O livro é dedicado às instituições que fazem parte do Programa Pontos de Memória, nomeados como "resistentes culturais". Os agradecimentos são voltados para instituições do governo e organismos internacionais; Ibram, Ministério da Justiça e OEI.

Entretanto, o empreendimento não se resume às relações governamentais. O conteúdo do livro é feito a partir do depoimento dos moradores das três favelas que cederam suas casas para a produção do circuito. Isso demonstra que a produção de uma imaginação para aquela comunidade tem como interlocutores tanto os agentes "de fora" da favela quanto os "de dentro".

A análise de seu conteúdo permite refletir sobre as maneiras pelas quais os gestores MUF produzem novas imaginações para seu território. O texto "Eu: Território do Museu de Favela" é bastante peculiar ao revelar as intenções e proposições desses autores para o museu, este que, na concepção deles, é todo o território. Narrando como se fosse o próprio morro, apresenta as visões dos autores sobre as favelas em questão e sobre a comunidade imaginada que almejam produzir. Acompanhamos, dessa forma, uma narrativa em primeira pessoa, na qual o morro é tomado como indivíduo e metáfora do corpo. Esta estratégia fica mais explícita quando analisamos a Figura 1, uma ilustração da primeira página do texto.

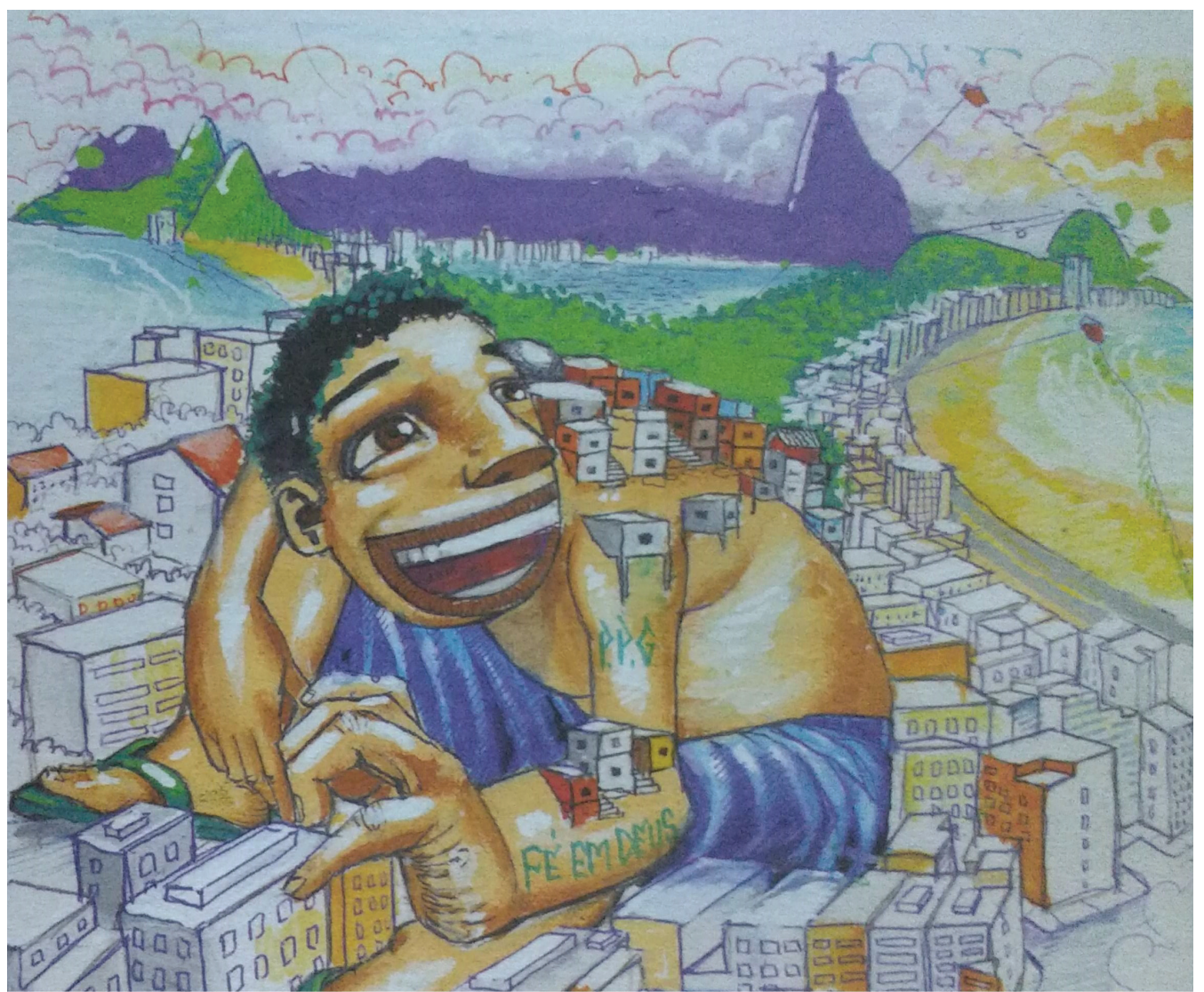

Figura 1: Ilustração do texto "Eu: território do Museu de Favela" Fonte: Loureiro, Pinto e Silva (2012, p. 29). 
$\mathrm{Na}$ Figura 1, observa-se que o rapaz carrega em suas costas as moradias que ocupam o morro. É preciso reparar que o rapaz está vestido de bermudas e chinelo de dedo, vestimenta que produz a identificação com os moradores reais, que habitam o morro. Esta identificação também é produzida pelas feições do corpo que simboliza o morro: os cabelos crespos e a pele negra remetem às características de grande parte da população que habita aquelas favelas, formada, basicamente, por negros, migrantes dos estados da região nordeste do Brasil e seus descendentes.

A estratégia de corporificar o morro produz um intenso efeito de humanização, que se aproxima das experiências das pessoas que o ocupam. Ao longo do texto, esta estratégia discursiva promove a aproximação entre o morro e os moradores. Em certo ponto, o morro "fala": "Sofri compressões, trações e torções até chegar nessa minha forma. Os homens que me ocupam também passaram por compressões, trações e torções. As minhas de origem geológica, as deles, de origem social" (LOUREIRO; PINTO; SILVA, 2012, p. 30).

Segundo o ponto de vista defendido no texto, ambos os corpos são sujeitos aos enquadramentos das estruturas que lhes são externas. $\mathrm{O}$ morro está sujeito às estruturas de origem geológica que o regulam. As pessoas, tais como o morro, passam pelo "assujeitamento" da estrutura que as condiciona; porém, esta é de ordem social. ${ }^{6}$ Esta passagem é particularmente interessante para refletir sobre as maneiras pelas quais o grupo produz interpretações sobre suas realidades. Uma "interpretação estruturalista" da realidade, na qual tanto as pessoas quanto o morro, equiparados, sofrem as sujeições da estrutura. Sozinhos, não podem alterar esta estrutura, mas exercem sua agência ao denunciar que ela existe e é injusta. É, portanto, uma representação que carrega forte caráter de denúncia e posicionamento político. $\mathrm{O}$ texto fala para quem não conhece aquela realidade, em um esforço de produzir pontes de comunicação com agentes externos e criar visibilidade para as dificuldades enfrentadas por quem é do morro.

Falando sobre sua história, no início do texto, o morro "reclama" das 5 mil moradias que ocupam suas encostas, articulando uma narrativa de intenso sofrimento.

Sinto-me pesado, me pesam, sofro de pressão alta sobre minhas encostas. Já sofri um derrame, não consegui segurar uma caixa-d’água no alto de minhas encostas. [...] Se prestassem atenção, perceberiam que, apesar de forte eu tenho os meus limites. (LOUREIRO; PINTO; SILVA, 2012, p. 39).

Entretanto, mais à frente, essa posição que parece uma hostilidade com os moradores transforma-se em solidariedade: "[...] compreendo a favela que me cobre como solução de moradia, uma escolha na falta de escolha" (LOUREIRO; PINTO; SILVA, 2012, p. 40). A partir de então, o morro toma seu partido em favor dos moradores, afirmando-os como o lado mais frágil de uma "estrutura social", de onde viria sua vulnerabilidade. Nesse sentido, afirma ter aprendido "[...] que entre os homens também há predadores e predados. Que, na ausência de Estado, prevalece a lei do mais forte" (LOUREIRO; PINTO; SILVA, 2012, p. 40). O morro assume, então, uma postura solidária diante dos moradores que ocupam suas encostas.

Nesse ponto, entra na narrativa produzida pelos gestores do MUF um agente que estava, até então, não nomeado no texto - o Estado - por meio da denúncia de sua suposta ausência. Entretanto, esta retórica da ausência do Estado precisa ser problematizada. Encontramos registros de sua ação nestes territórios em diversos momentos, ainda que não tenha desenvolvido políticas suficientes, nem permanentes. O Estado surge também como uma entidade abstrata, desconsiderando, por exemplo, que a existência do próprio livro em que o texto está publicado foi possibilitada pela ação de determinadas pessoas que fazem parte de instituições de governo. Nesse sentido, cabe considerar que, ainda que não diretamente nomeados, os agentes de instituições de governo atuam diretamente na produção das novas imaginações para o Pavão-Pavãozinho e Cantagalo propostas pelo MUF.

É importante chamar atenção para outro instrumento de produção de imaginações de que os gestores do MUF lançam mão, estratégia de poder 
inegável na produção de comunidades imaginadas: o mapa. Benedict Anderson, refletindo sobre as imagens produzidas pelos Estados coloniais da África e da Ásia, defende que estas foram modeladas não somente a partir dos estados dinásticos europeus. Uma "genealogia próxima" era necessária na composição da gramática que possibilitaria a produção destas imagens. Para o autor:

[...] poucas coisas mostram mais claramente essa gramática do que três instituições de poder, as quais, embora inventadas antes de meados do século XIX, modificaram a sua forma e função quando as zonas colonizadas ingressaram na era da reprodução mecânica. Essas três instituições são o censo, o mapa e o museu: juntas, elas moldaram profundamente a maneira pela qual o Estado colonial imaginava o seu domínio - a natureza dos seres humanos por ele governados, a geografia do seu território e a legitimidade do seu passado. (ANDERSON, 2008, p. 227)

Guardadas as diferenças de escala e temporalidade entre os mapas produzidos pelos estados coloniais do século XIX, objetos de Anderson, e os mapas produzidos pelo Museu de Favela em diálogo com agências do governo brasileiro no século XXI, suas reflexões colaboram para a compreensão dos elementos que temos em tela.

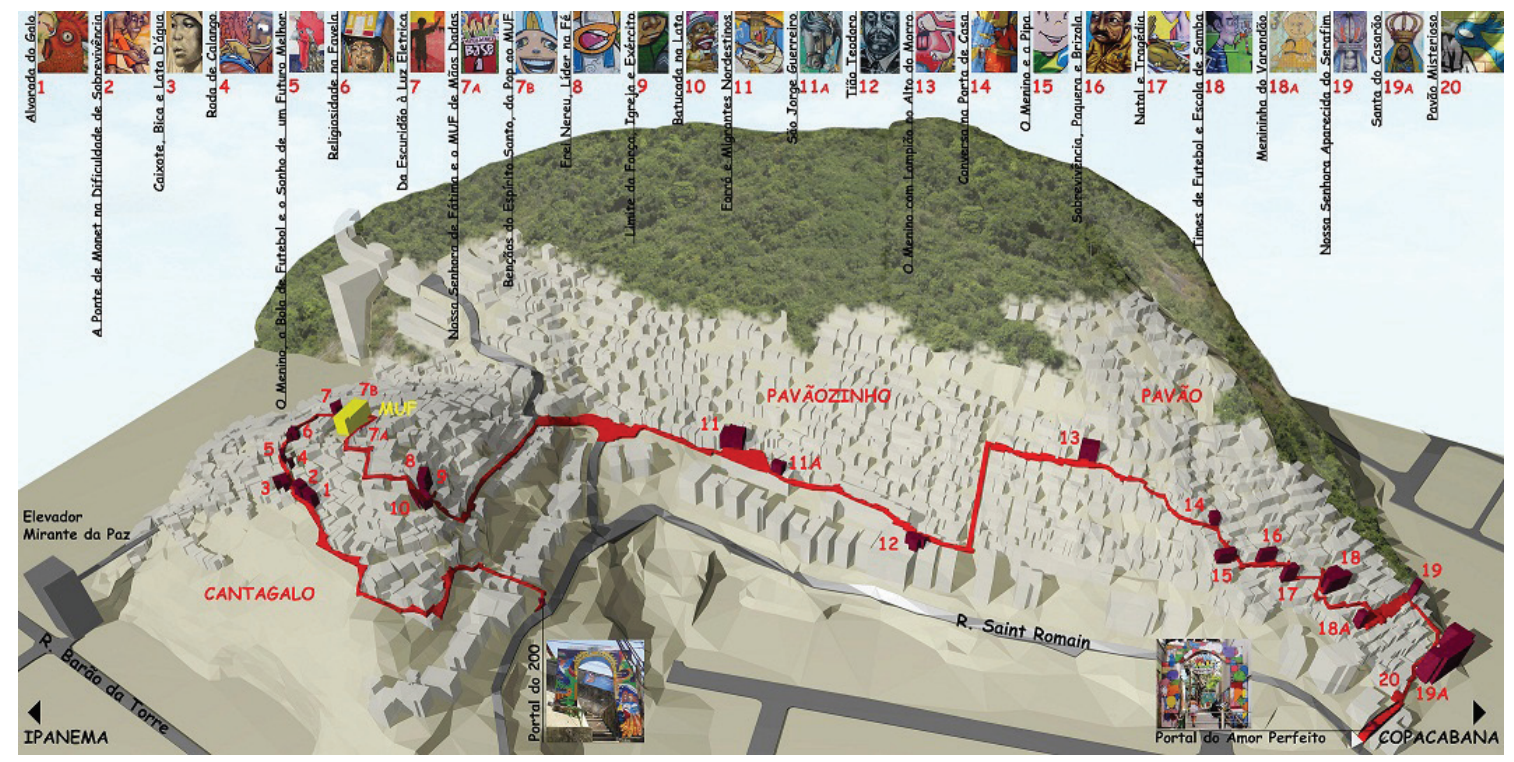

Figura 2: Mapa do Circuito das Casas Tela

Fonte: Loureiro, Pinto e Silva (2012, p. 66-67).

No mapa da Figura 2, a vista enquadra a totalidade da ocupação do maciço do Cantagalo. As duas favelas, Cantagalo e Pavão-Pavãozinho, aparecem como um todo contínuo. Há o fato de as construções de ambas as favelas terem se espraiado pela encosta até tornar imperceptível qualquer separação entre os territórios. Entretanto, para além desse fato, é preciso considerar os mapas como formas de representar que revelam as escolhas daqueles que os produziram dentro de um universo de possibilidades. Dessa forma, ligadas pela representação cartográfica proposta, as favelas repetem o formato "Complexo Pavão-Pavãozinho-
Cantagalo", que atende a um projeto que pensa as duas favelas como um todo. A linha vermelha que cruza o maciço pelo meio das moradias, iniciando em Ipanema e terminando em Copacabana, demarca o "Circuito das Casas Tela". Este circuito atravessa e unifica os dois territórios por meio das memórias dos moradores representadas pelos grafites nas fachadas das casas.

Entretanto, Juliana Blasi Cunha (2014) demonstra que, historicamente, as relações entre os moradores das duas favelas foram produzidas com base em rivalidades e diferenciações. A despeito das diferenças que separavam Pavão-Pavãozinho 
e Cantagalo, como afirma a autora, a chegada do grupo de narcotraficantes do Comando Vermelho foi importante elemento para a produção da unificação desse território:

[...] a relação de rivalidade entre Cantagalo e Pavão-Pavãozinho é anterior ao início do tráfico na região e, inclusive, orientou a forma como os antigos bandidos locais, as chamadas "quadrilhas", atuaram na região. Tais quadrilhas, no entanto, foram substituídas pelo Comando Vermelho, que, após dominar os pontos de venda de drogas das duas favelas, buscou, ao seu modo, unificá-las, alterando a dinâmica da vida local. (CUNHA, 2014, p. 146).

A unidade entre os territórios de PavãoPavãozinho e Cantagalo, produzida primeiramente pelos agentes do tráfico de drogas, foi apropriada pelo Estado. Esta apropriação seguramente se efetiva por meio da ação policial naquela região que, para traçar as estratégias de enfrentamento ao tráfico, levou em consideração a sua maneira de operar o território. Posteriormente, foi adotado o formato "Complexo do Pavão-PavãozinhoCantagalo" para o desenvolvimento de ações do Programa de Aceleração do Crescimento, uma atualização daquela unidade dos territórios produzida pelo tráfico que impactou o desenho das ações promovidas pelo MUF.

Outras fontes demonstram como a proposta do PAC informou a produção desta representação unificada do território de Pavão-Pavãozinho e Cantagalo. Rita de Cássia aborda essa questão em entrevista (SANTOS, 2014). Segundo a diretora do MUF, antes da chegada do PAC, as ações desenvolvidas individualmente pelos agentes que se mobilizaram para a criação do museu eram concentradas em seu próprio território. E, antes das ações do PAC, segundo ela, essa percepção unificada das três favelas como um único Complexo não era mobilizada no desenvolvimento de ações culturais.

Acompanho Juliana Blasi Cunha na sua afirmação de que existe um "nós relacional" entre os moradores de Pavão-Pavãozinho e Cantangalo. A autora desenvolve esta ideia para analisar as relações entre os moradores do Pavão-Pavãozinho e do Cantagalo no contexto da implantação da UPP e da segunda fase do PAC naquele território. Afirma que

[...] o sentimento de pertença dos moradores à favela é relacional. Quase sempre se sentem pertencendo a uma ou outra favela, marcando as diferenças entre eles. Em algumas situações, no entanto, é possível que esse sentimento de pertencimento assuma um sentido mais amplo de todo o "Complexo Pavão - Pavãozin ho - Cantagalo”. (CUNHA, 2014, p. 113).

Também acredito que esse sentimento de pertença relacional exista entre os gestores do MUF, e isso impacta as maneiras de realizar o trabalho do museu. Assim, se a instituição do museu busca consolidar uma unificação dos territórios sob a forma "Complexo Pavão-Pavãozinho-Cantagalo", na prática de seus gestores pode ser ou não acionada, dando lugar a possibilidades diversas para a produção de sua identificação.

Em princípio, é possível considerar a representação do território no formato "Complexo Pavão-Pavãozinho-Cantagalo" como uma imposição do Estado diante dos moradores da favela em questão. No entanto, entendo ser importante perceber como os gestores do MUF se movimentam diante dessa imposição com o objetivo de alcançar ganhos frente à política pública que lhes foi apresentada. Assim, definem seu território de atuação e criam suas representações a partir do que foi estabelecido pelo PAC. Sabendo que a gramática da política vigente impunha que eles se pensassem como complexo de favelas, e não separados em suas especificidades territoriais, organizaram seu empreendimento nesse sentido. Mobilizar as categorias de acordo com a política em vigor seria, talvez, a única possibilidade de diálogo com o Estado e de ver atendidas suas demandas.

Ao mesmo tempo, recuperando a ideia de que há um "nós relacional", é importante notar que o formato "complexo de favelas" não é o único de que lança mão o museu para representar seu território. É o que se verifica ao analisarmos a Figura 3, outro mapa que compõe o livro "Circuito das Casas Tela". 


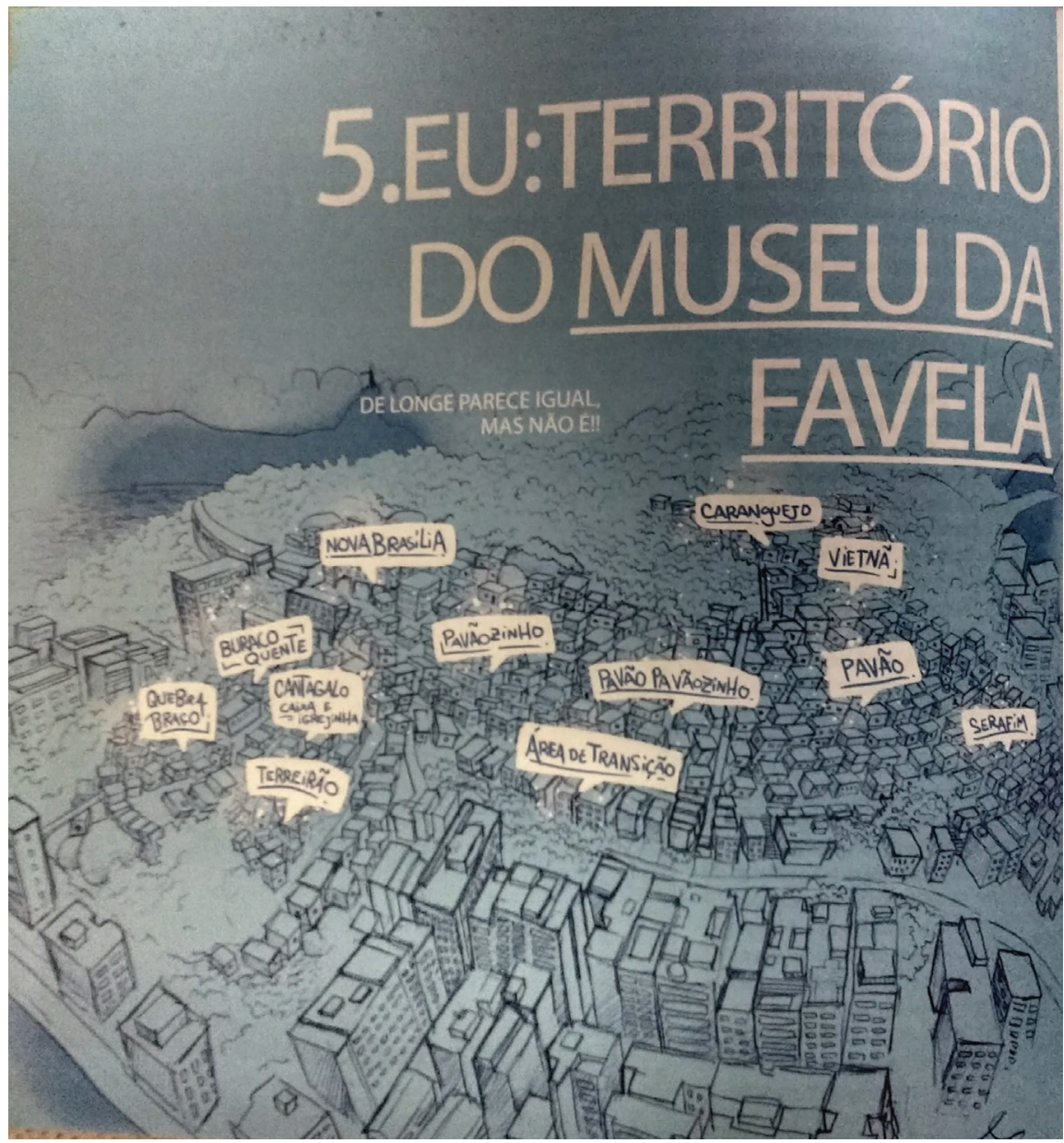

Figura 3: Representação do território do MUF com suas subdivisões

Fonte: Loureiro, Pinto e Silva (2012, p. 28)

Este mapa também apresenta o enquadramento do alto, que representa a totalidade da ocupação do maciço. Entretanto, a divisão espacial que se evidencia é mais complexa. Aparecem nele os nomes das localidades que subdividem as favelas. Estes nomes foram produzidos por seus moradores na prática de habitar aqueles espaços, como se vê em um trecho do texto "Eu: Território do Museu de Favela":

Os homens criaram nomes interessantes para partes menores de mim. Serafim tem esse nome por conta do Hotel Serafim, o Vietnã porque seus ocupantes chegaram muito pobres e meio esfarrapados, pareciam voltar da Guerra do Vietnã, Caranguejo lá no alto, porque começar a vida aí era (e ainda é) tão penoso que parecia que se andava para trás, tal um caranguejo; Quebra-braço, porque muita gente se acidenta nessa ocupação, de cima das lajes e pirambeiras, Caixa d’Água por motivo do reservatório da CEDAE, Nova Brasília [...]. (LOUREIRO; PINTO; SILVA; 2012, p. 29).

No centro da imagem, lê-se a frase "De longe parece igual, mas não é!!’. A inscrição revela a existência de representações específicas dos territórios em questão somente apreensíveis quando se está de dentro da favela ou se observa de perto seu espaço, mas não somente isso. Revela a proposta de afirmar especificidades dentro de um programa de governo em que a representação da favela planifica e homogeneíza as diferenças. Mostra que há também uma concorrência entre as representações que projetam consolidar no MUF e as que são produzidas pelos agentes de Estado mais ligados ao planejamento e à segurança pública. 
A existência das duas formas de mobilizar as representações dos espaços em questão não configura uma contradição. Mostra que é possível para as pessoas que estão à frente do museu transitar por múltiplas definições, mobilizando uma ou outra em momentos específicos, a depender de sobre o que e com quem se fala.

Como pretendi demonstrar, as representações articuladas pelo MUF produzem uma imaginação para aquele território, importante aspecto do seu projeto museal. $\mathrm{Na}$ experiência do MUF, busca-se desafiar a imagem das favelas produzida, no decorrer do século XX, por diversos meios, na chave da carência associada à violência. Como resultado, almeja desvelar as favelas, consolidando-as como espaços dotados de passado relevante ainda que desconhecido da cidade.

Em suas "práticas espacializantes", os sujeitos mobilizados em torno do MUF produzem diversas maneiras de imaginar as favelas do Pavão-Pavãozinho e Cantagalo. Apropriamse de representações produzidas de fora para dentro ao mesmo tempo em que reafirmam suas próprias construções simbólicas que constituem a espacialidade daquele museu.

Ao lançarem, ao centro da representação, as formas de nomear elaboradas na experiência dos moradores em habitar o território, tornam a própria experiência um patrimônio do museu. Buscam comunicar aos sujeitos que a constituem que suas práticas devem ser reconhecidas e valorizadas; portanto, é uma comunidade detentora de memória, um importante capital. Ao mesmo tempo, essas pessoas que se mobilizaram reafirmam aos de fora que a favela é parte relevante da cidade, que seus modos de habitar devem ser reconhecidos, os seus patrimônios preservados e os seus direitos respeitados.

\section{Notas}

1 Seção “O PAC”. Disponível em: <www.pac.gov.br>. Acesso em: 24 fev. 2016.

2 Informações retiradas de: "Informação pública PAC Comunidade Pavão-Pavãozinho/Cantagalo Urbanização", disponível em: <http://www.rj.gov.br/web/ informacaopublica/exibeconteudo?article- id=1036865> e de Cunha, 2014.
3 Além do projeto desenvolvido no Pavão-Pavãozinho e Cantagalo, alguns dos projetos conduzidos pela empresa são: o "Programa de Regularização Urbanística e Fundiária do Complexo da Tijuca" e o "Programa Social Morar Carioca - Babilônia e Chapéu Mangueira”. A empresa mantém uma página na internet; porém, não há informações atualizadas: www.kal.com.br. Os veículos em que encontramos informações mais recentes sobre o PAC Social no Pavão-Pavãozinho e Cantagalo são as páginas na rede social Facebook mantidas pela empresa: "KAL Projetos e Territórios" e "PAC Social Pavão-Pavãozinho e Cantagalo". Todos os acessos em: 24 fev. 2016.

4 “Sobre o MUF". Disponível em: <http://www. museudefavela.org/sobre-o-muf/sobre-o-muf>. Acesso em: 9 mar. 2016.

5 A Organização dos Estados Iberoamericanosé, conforme consta em seu site, "[...] um organismo internacional de caráter governamental para a cooperação entre os países ibero-americanos no campo da educação, da ciência, da tecnologia e da cultura no contexto do desenvolvimento integral, da democracia e da integração regional". Com sede em Madri, Espanha, é composta pelos seguintes países: Argentina, Bolívia, Brasil, Colômbia, Costa Rica, Cuba, Chile, República Dominicana, Equador, El Salvador, Espanha, Guatemala, Guiné Equatorial, Honduras, México, Nicarágua, Panamá, Paraguai, Peru, Portugal, Uruguai e Venezuela. Informações disponíveis no texto "Quem somos", em: <www.oei.org.br>. Acesso em: 16 fev. 2016.

6 Antônio Carlos de Souza Lima utiliza "assujeitamento" e assim o justifica: "[...] traduzi propositalmente subject no sentido de subordinado a um poder - por assujeitado (assujeitamento), de forma a marcar ao mesmo tempo a diferença e a duplicidade contidas no termo sujeito, mais claramente expressas em inglês" (LIMA, 1989, p. 85). É nesse sentido que uso o termo.

\section{Referências}

ANDERSON, Benedict. Comunidades Imaginadas. São Paulo: Companhia das Letras, 2008.

CUNHA, Juliana Blasi. "Nossa casaca é dupla face": dinâmica sócio-espacial e política local no processo de implementação do PAC e da UPP em uma favela da cidade do Rio de Janeiro. 2014. 293 f. Tese (Doutorado em Antropologia Social) - Programa de Pós-Graduação em Antropologia Social, Universidade de São Paulo, São Paulo, 2014.

DE CERTEAU, Michel. A invenção do cotidiano - as artes do fazer. Rio de Janeiro: Editora Vozes, 2011. 
LIMA, Antonio Carlos de Souza. Um Grande Cerco de Paz. Poder Tutelar, Indianidade e Formação do Estado no Brasil. Petrópolis: Vozes, 1995.

LOUREIRO, Kátia; PINTO, Rita de Cássia S.; SILVA, Carlos Esquivel G. da. Circuito das CasasTela, caminhos de vida no Museu de Favela. Rio de Janeiro: Museu de Favela, 2012.

SANTOS, Rita de Cássia dos. Entrevista [agosto de 2014]. Entrevistadora: Aline dos Santos Portilho. Rio de Janeiro, 2014. 1 arquivo mp3 (109 min).
VALLADARES, Licia do Prado. A invenção da favela: do mito de origem à favela.com. Rio de Janeiro: Editora FGV, 2005.

VARINE, Hugues. O museu comunitário é herético? 2005. Disponível em: <http://www. hugues-devarine.eu/textes-inedits/38-2005-omuseu-comunitario-e-heretico-.html $>$. Acesso em: 9 mar. 2016. 